\title{
Fuel Saving on Diesel Genset using PV/Battery Spike Cutting in Remote Area Microgrid
}

\author{
Tinton Dwi Atmaja ${ }^{1, *}$, Ant Ardath Kristi ${ }^{1}$, Agus Risdiyanto ${ }^{1}$, Bambang Susanto ${ }^{1}$, Dian Andriani ${ }^{1}$, Makoto Fujita $^{2}$, and \\ Atsushi Hirono ${ }^{2}$ \\ ${ }^{1}$ Research Centre for Electrical Power and Mechatronics, Indonesian Institute of Sciences, Komp. LIPI Bandung, \\ Jl. Sangkuriang, Gd. 20, Lt. 2, Bandung 40135, Indonesia \\ ${ }^{2}$ Murata Manufacturing, Co. Ltd. 10-1, Higashikotari 1-chome, Nagaokakyo-shi, Kyoto 617-8555, Japan
}

\begin{abstract}
Diesel Generator set was found to be a favorite power generator in a remote area. In this area, diesel genset usually consumes a significant amount of diesel fuel with higher fuel price than an urban area. Diesel Generator capacity conventionally prepared twice bigger or more than the existing load to prevent any load spike from designated equipment. This work implements an Energy Management System to cut the spike with the support from battery storage unit and photovoltaic module. Once the Energy Management System cut the load spike using battery/photovoltaics, Diesel Generator loads no longer need to be irrelevantly bigger than the existing load. The current experiment in the remote island at Raja Ampat archipelago indicates that the using of $80 \mathrm{kVA}$ Diesel Generator can be reduced to $42 \mathrm{kVA}$ Diesel Generator. This Diesel Generator replacement induces fuel consumption up to $50 \%$. With this designed work, a smart microgrid with PV-Battery-Diesel can be installed in a designated remote area with lower fuel consumption.
\end{abstract}

Keywords: Battery storage, diesel generator set, photovoltaic, smart inverter, smart microgrid.

\section{Introduction}

Microgrid installment in a remote area such as a small island or an isolated village in the middle of the jungle is a very significant aspect for the local people to get electricity. As the lower layer of smart grid [1], the microgrid is self-supplied electricity distributed system consisting a power generation system, having its own storage system, isolated load and limited coverage area. Diesel genset (DG), especially small capacity from $10 \mathrm{kVA}$ to $80 \mathrm{kVA}$, is the most favorite power generation system in the remote area. DG considered portable to be mobile in harsh condition and easily installed or relocated within remote area far from the main utility grid. Figure 1 shows the 50 kVA DG installed in Lereh, Yadauw, a village $100 \mathrm{~km}$ inside Papua jungle, Indonesia.

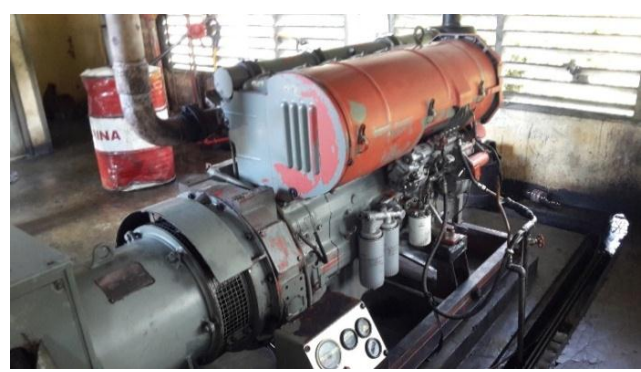

Fig. 1. Diesel generator set as power sources in remote area.

\footnotetext{
${ }^{*}$ Corresponding author: tinton_dwi@yahoo.com
} 
DG has a reasonable price to buy but relatively expensive to maintain. However, its capability to operate at low levels [2] made it a reasonable choice as an off grid power source. Once installed, DG can run continuously [3] with minimum maintenance effort rather than other power generation system. There are some previous researches on increasing DG performance by connecting the additional equipment or integrating the renewable energy (RE) source to assist DG unit. Previous research by Wresta et al.[4] mention that it is highly potential to implement spark ignition DG to increase the DG efficiency. As the potential of RE combination, wind power, and solar energy is the most available renewable sources in the remote area rather than rarely find hydro power or expensive tidal/wave power generation system.

This work was focused in a remote area near the equator line with sufficient solar radiance but low potential of wind power. Therefore, solar power is the main RE that supporting this work. Concentrated solar power (CSP) was once considered as possible energy backup. Previous research has been conducted on CSP installation with designated thermal storage and additional layer [5]. However, the size and the portability of CSP power plant cannot overcome photovoltaic solar farm.

Photovoltaic (PV) systems are considered reliable, cost-effective and environmentally friendly energy power systems especially in remote areas [6]. Figure 2 showed a PV installment in Abar Village, the remote area of Sentani Lake, Papua, Indonesia. Previous research for PV in an equatorial climate has been conducted by K.Y. Lau et al. [7]. It comes to attention that PV performance has been effected by the temperature, especially in tropical climate. Furthermore, the electrical efficiency and the power output of a PV module depend linearly on the operating temperature around PV cell [8].

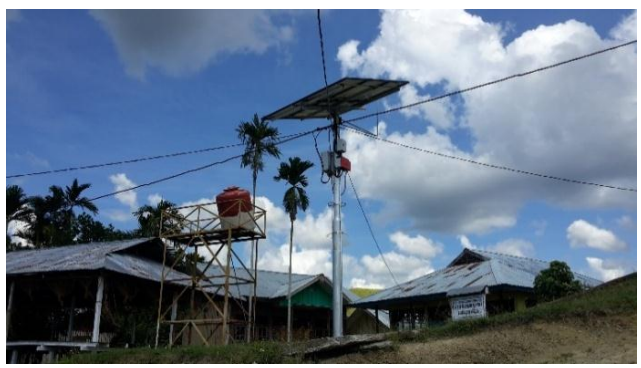

Fig. 2. PV module as renewable energy sources in remote area.

PV was also possible to be installed as building integrated photovoltaic (BIPV) [9]. Therefore, it can be attached in every part of the building aside of the rooftop, such as curtain wall, window sunshade, or balcony side. PV could also increase the energy harnessing by installing in the high vertical position [10]. However, this method only works if there is a highly elevated landscape contour (such as a cliff in sun direction) or high-rise building in the island (such as communication tower).

The main aim of this work is to integrate DG-Battery-PV into one responsive hybrid generation system successfully. The success of this work will bring significant impact on how to utilize solar power in a remote area microgrid. With this integration, there will be a reduction in electricity demand to the DG unit which means a decrease in DG capacity and resulted in fuel consumption reduction. Fuel saving has been considered as one important step to achieve sustainable smart microgrid with green energy sources.

\section{System configuration}

\subsection{Grid configuration}

Previous research had described the integration of PV and DG provides greater system reliability and reduces the cost of the generated energy by the system [11]. Another research by Kusakana [12] expressed that significant operation cost could be saved by combining batteries and photovoltaics into diesel genset. The previous design of PV/DG/Battery was provided with simple battery model [13], and optimization was also proposed by Noguera et al. [14]. Our work was designed with similar concept and goal where the primary load was primarily powered by the DG and supported by PV and batteries (Figure 3). The aerial view of the site can be found in Figure 4. 


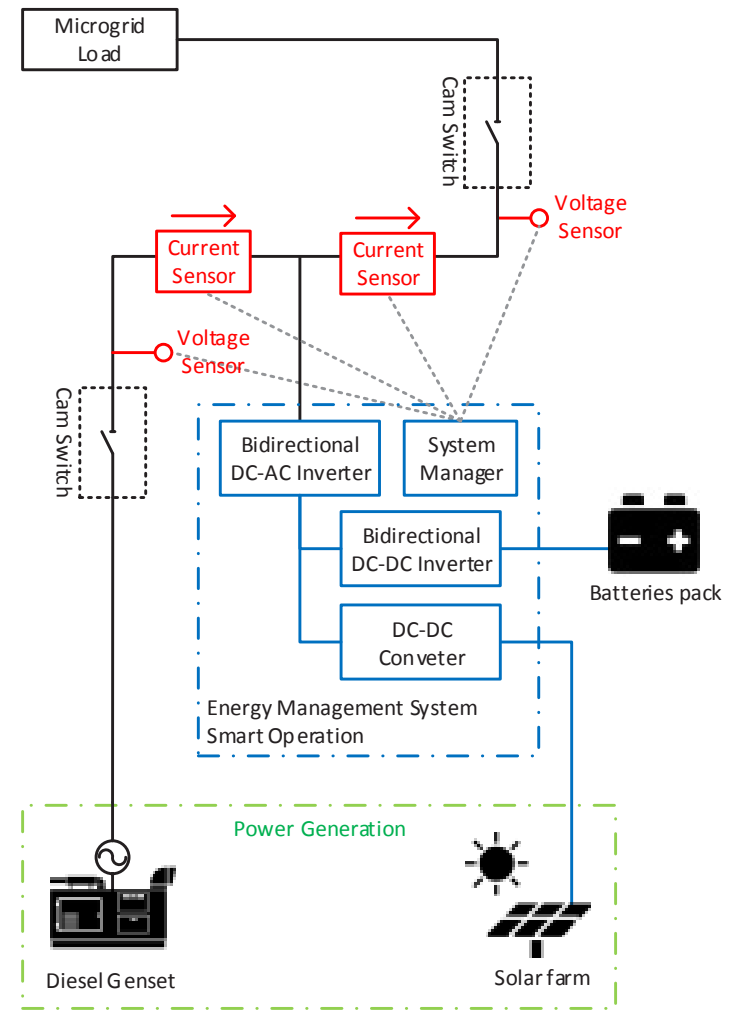

Fig. 3. Grid schematic.

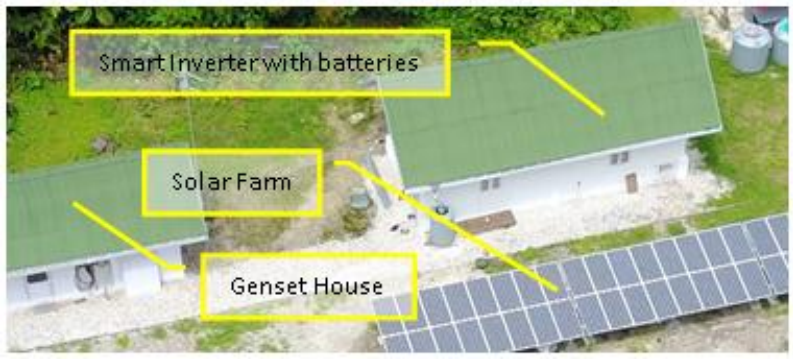

Fig. 4. Aerial view of experimental demo site.

In this site, the load was a research complex of Raja Ampat conservation area located in a remote island approximately $76 \mathrm{~km}$ offshore of West Papua mainland. The complex contains several offices, resort, and staff building equipped with air conditioning, refrigerators, and compressors. The main power came from diesel genset unit in the genset house. In this work, a laboratory was built to facilitate integration between the DGs and the renewable source (PV). Inside the laboratory, the smart inverter was installed to harness power from the PV and supplied to the site's microgrid. Battery rack was also placed inside the laboratory as the main energy storage from the solar farm and sometimes from the DG itself.

\subsection{Diesel genset and load profile}

Installed DG in the demo site was initially set to cover the whole settlement in the island (Figure 5). Furthermore, fuel cost estimation was calculated for a day by the non-linear quadratic function in Equation (1) [15]. 


$$
\sum_{j-1}^{N}\left(a P_{D G(j)}^{2}+b P_{D G(j)}^{2}+2\right)
$$

Where $\mathrm{N}$ is the number of sampling intervals within the operation range or period of the system; $\mathrm{a}, \mathrm{b}, \mathrm{c}$ is the fuel cost coefficients; $j$ is the $j$ th sampling interval; $P_{D G(j)}$ is the output power from the $D G$ at jth sampling interval; and $C_{f}$ is the price of $1 \mathrm{~L}$ of fuel.

Fig. 5. Diesel generator.

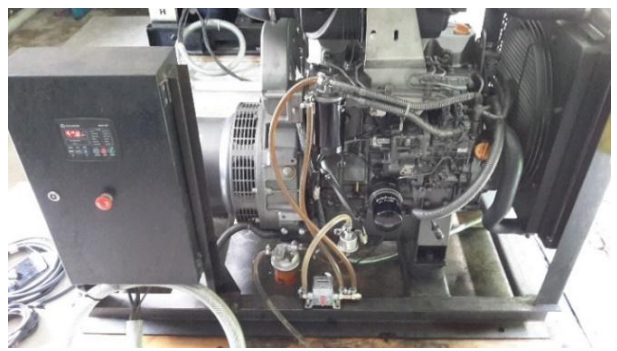

DG usually set to operate within $60 \%$ to $80 \%$ of its maximum capacity so the fuel consumption will be at its optimum rate and increase DG life span. This rate will determine how big is the capacity of the DG should be provided. Figure 6 shows the sample of the load profile of island. In steady condition, the load current will be between $60 \mathrm{~A}$ to 100 $\mathrm{A}$, however, because of the distinctive equipment such as compressor and oxygen mixer, there was a spike occurred that highlight the current up to $156 \mathrm{~A}$.

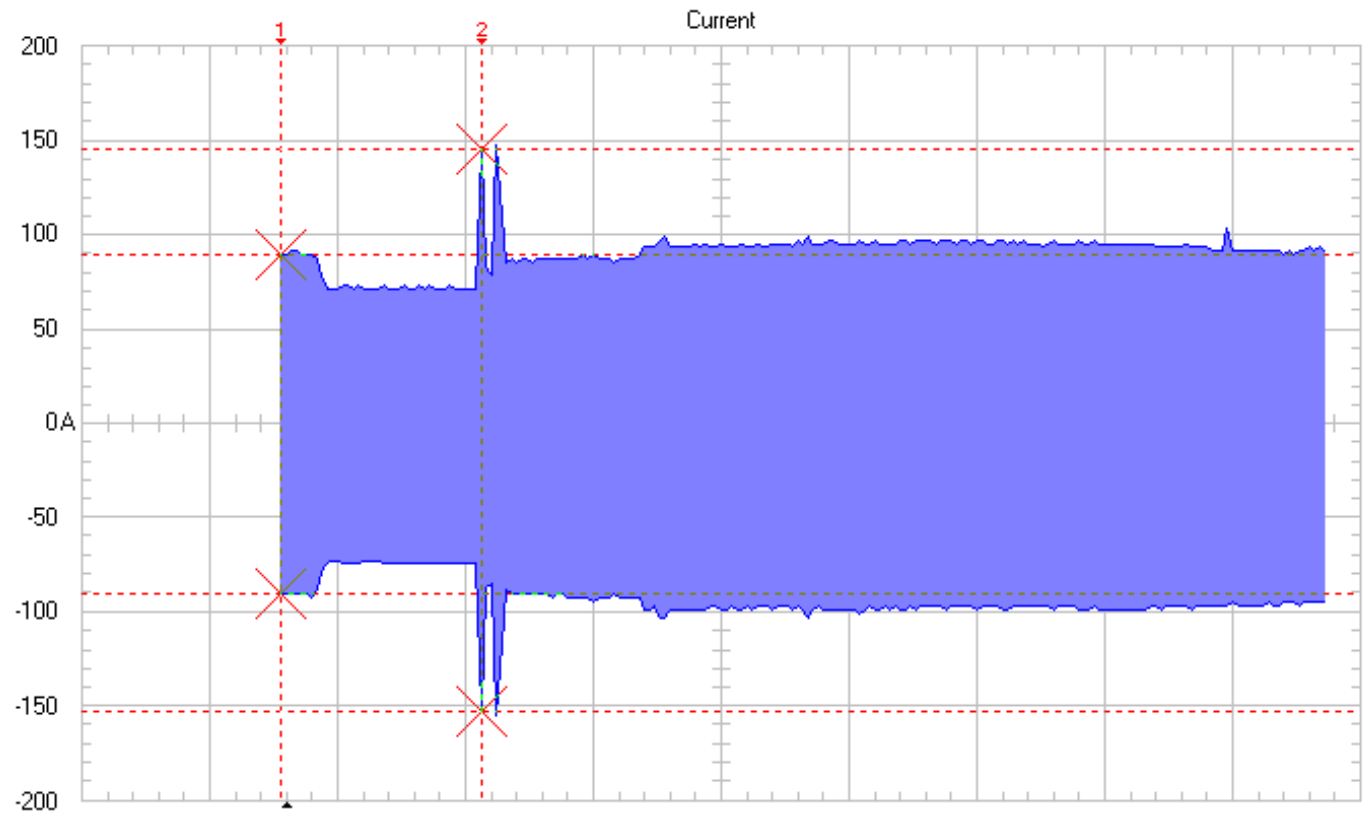

$-00: 00: 48.0$

30 s/Div

Fig. 6. Load spike.

The spike occurred every time the compressor started. It was happened for at least two to three second per spike. This spike had forced the owner to increase the capacity of the DG. Without the spike, a $42 \mathrm{kVA}$ DG will be sufficient, however, with the spike occurred, the owner should increase DG capacity up to $60 \mathrm{kVA}$ to avoid a possible blackout in the whole island. Even with the increased capacity of the DG, increasing power demand will make the DG operation 
become unstable and resulted in increased fuel consumption. As the power demand increased, the DG power load also increased and the fuel consumption has increased similarly.

\subsection{Energy management system}

An energy management system (EMS) was installed in the laboratory to assist the grid to cut the spike. The EMS consists of smart inverter unit and battery pack. The $3 \mathrm{~kW}$ Murata Smart Inverter was used in this work in order to facilitate the spike cutting and also later integrate the PV into the microgrid. Murata Smart Inverter was equipped with Murata battery unit. Every three batteries are packed along with one Battery Management System.

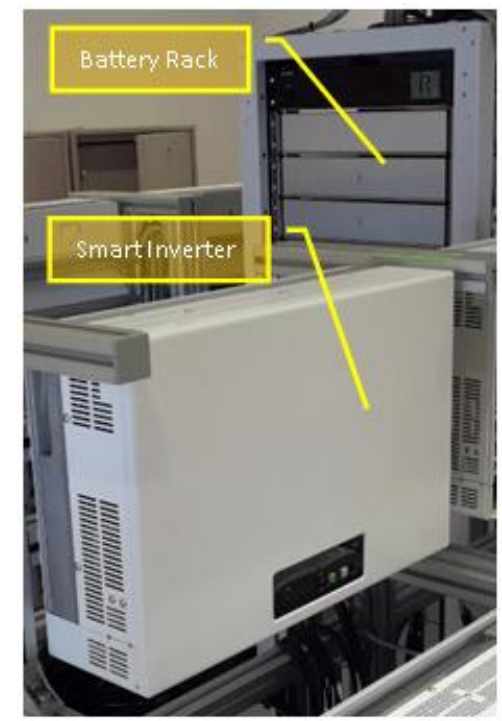

Fig. 7. EMS with smart inverter unit and battery pack.

At the time load spike is occurred, the EMS unit will draw the energy from the batteries -if available- to consume the spike instead of using the energy from the DG. The dynamics of the battery SOC (state of charge) can be expressed in equation (2) [16].

$$
S O C_{(J+1)}=S O C_{(J)}-t_{s} \frac{\eta_{B a t}}{E_{n o m}} \times P_{B a t_{(j)}}
$$

Where SOC is the state of charge of the battery; $\mathrm{h}_{\mathrm{Bat}}$ is the battery charging or discharging efficiency; $\mathrm{E}_{\mathrm{nom}}$ is the battery system nominal energy; and $\mathrm{P}_{\mathrm{Bat}}$ is the power flowing from the battery system.

\subsection{Solar farm to support the EMS}

As the island located near the equator, solar power was the most possible available renewable energy on the site. The monocrystalline solar module was installed near the laboratory and integrated to the grid via the EMS unit. The installed capacity reaches up to $9 \mathrm{kWh}$, and the average power has reached out to $7.4 \mathrm{kWh}$. The output power of the PV system can be calculated using Equation (3) [17].

$P_{P V}=A_{P V} \times \eta_{P V} \times \int_{t_{0}}^{t} I(t) \times f(t) \times d t$ 
Where APV is the total area of the photovoltaic generator $\left(\mathrm{m}^{2}\right) ; \mathrm{h}_{\mathrm{PV}}$ is the module efficiency; I is the hourly irradiance $\left(\mathrm{kWh} / \mathrm{m}^{2}\right)$; and $\mathrm{f}(\mathrm{t})$ is the radiance density.

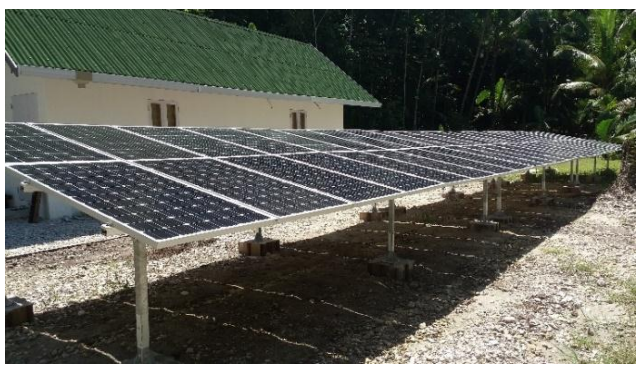

Fig. 8. Solar farm.

\section{Result and discussion}

The primary objective of this work was conducting fuel saving from DG unit. The first method was to cut the spike when specific equipment was started. The second method was facilitating renewable energy to support the DG, especially in the peak time so the DG would still work in its optimum workload.

\subsection{Cutting the load spike by the EMS}

The primary function of EMS unit was to eliminate the load spike occurred when specific equipment was started. The EMS was responsible for cutting the load spike using the energy available in the battery storage unit. The EMS had placed a current sensor on the load side of the microgrid and another current sensor at the power source side of the microgrid. Once the sensor has detected an increasing power demand, the smart inverter would consider that a spike was occurred and would instruct the battery pack to discharge energy in similar amount with the spike. In this condition, the energy amount of the spike would be no longer requested to the DG. Figure 9 illustrates that the spike above a critical point has been cut.

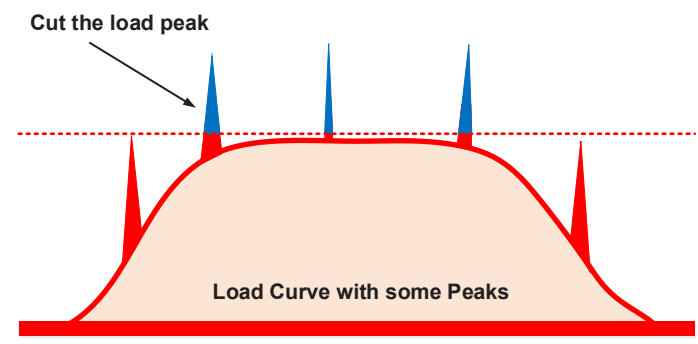

Fig. 9. The illustration of spike cutting by the battery.

As the spike was no longer drawn energy from DG unit, the DG would be operating steadily at its optimum rate. The steady operation means that DG's fuel consumption would also be steady with minimum possibility of sudden increase of fuel consumption.

\subsection{RE integration via EMS}

The EMS unit can be operated without connected to RE sources. However, with PV connected to the EMS outlet, the electricity supply has increased rather than merely depending on the battery pack. Facilitating the PV as the backup energy for the microgrid was the secondary function of the EMS unit and become significant support to the DG power grid.

There were two scenarios for utilizing the electricity from the solar farm. The first scenario was directly supplied that the electricity harnessed in the daylight — approximately from 8.30 am to $4: 30 \mathrm{pm}$ - to the grid. It will help the DG to operate without surpassing DG maximum capacity. In this scenario, battery pack assistance was not necessarily needed. 
Figure 10 showed how the electricity from the PV absorbed the demand at the peak time on behalf of the DG. The second scenario was the use of battery pack to store electricity that harnessed in the daylight. This electricity would be used only at the peak time in daytime or nighttime. In this scenario, battery pack was an absolute requirement, and the bigger the capacity of the battery packs the better the coverage of the peak time. Nevertheless, both scenarios would prevent the DG unit to unnecessarily operate at its maximum rate where the fuel consumption was higher.

\subsection{Fuel consumption reduction}

Cutting spike had reduced the requested peak limit and integrated solar farm had shaved off the peak demand. These two methods change the minimum requirement of DG capacity. Along the reduction of the peak load profile, the operating DG was no longer necessary to be a big one $(60 \mathrm{kVA})$. Altogether, DG unit with $42 \mathrm{kVA}$ capacities was sufficient to cover all the electricity demand of the demo site. Figure 11 showed how DG capacity could be reduced from $60 \mathrm{kVA}$ to $42 \mathrm{kVA}$. After this capacity reduction, the fuel consumption of smaller DG (42 kVA) had been lower than the higher DG $(60 \mathrm{kVA})$. In this experiment, the fuel saving reduction of smaller DG could reach $30 \%$ to $40 \%$ from the initial bigger DG, respectively.

\subsection{Further optimization}

Hybrid power generation had a high potential to be implemented in a remote area either in a fixed or mobile platform. The mobile platform of PV-DG-Battery would be suitable for important remote sites such as sea vessel, zero energy building/complex, mobile military compound, or mobile rescue unit. However, previous research by Montreal et al. [18] had mentioned that PV integration would not always give advantages on the mobile microgrid, it depended on how long was the travel period. For $90 \mathrm{~d}$ or more travel period, PV panel integration with battery would have sufficient weight to affect a reasonable cost of the travel. However, in shorter traveling time-30 d to $60 \mathrm{~d}$, the optimum system which reaches minimum weigh for reasonable travel cost should not include PV panel.

When it came to fixed/mobile vital facility such as mobile military compound, security should be as much consideration as the hybrid installation. Therefore, part of the research should be covering microgrid security system whether it was online or offline [19]. DG-battery was undeniably favorite combination for off-grid isolated microgrid. However, this combination could not be launched immediately as it needed a slight several second to reach stable condition [20]. Therefore, aside of the hybrid system cost, the use of more sophisticated energy storage system would bring significant advantages. Superconductor (SC) was one of energy storage technology alternative that could resist against the shortage of PV array power and batteries. SC also provided a quick response and extraordinary instantaneous output power. However, SC energy capacity, unfortunately, was shallow and eventually had a high self-discharge current [21].

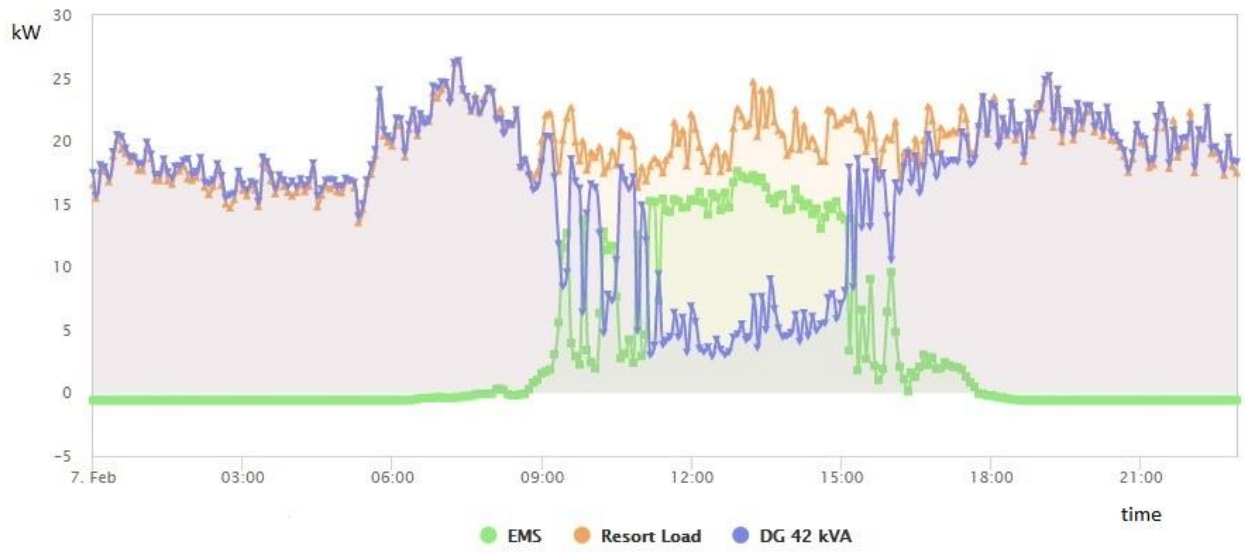

Fig. 10. EMS is facilitating the energy from $P V$ to reduce DG power demand. 


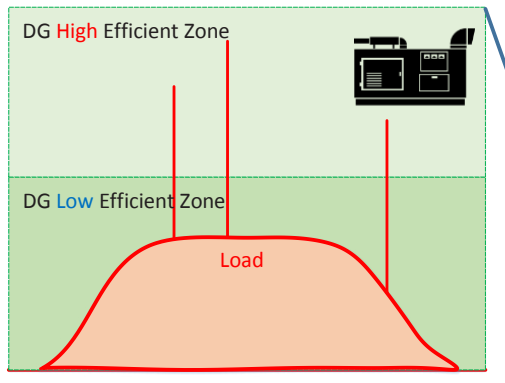

(a)

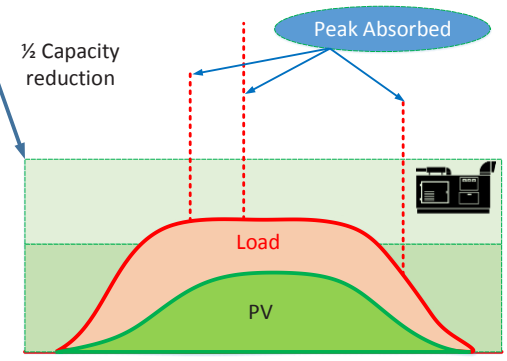

(b)

Fig. 11. Diesel genset capacity reduction before (a) and after (b) cutting spike and PV integration.

\section{CONCLUSION}

This work had integrated PV and battery into DG's power grid to become a hybrid power generation. The integration was using an EMS unit consisted of a smart inverted unit which could cut off any occurring load spike and also facilitated energy supply from solar farm to the DG's microgrid. The spike cut off was conducted by the EMS unit using the available power in the battery to absorb energy spike so it would not burden the DG power output. The EMS unit could help DG unit by absorbing peak energy demand using PV energy directly at the same time or store the energy in the battery and discharge it to be used at any necessary time. The spike cut off and RE integration would reduce the required capacity of the DG. The replacement of $62 \mathrm{kVA}$ DG with the $42 \mathrm{kVA}$ DG means a reduction of fuel consumption regarding DG's capacity difference. The fuel saving was approximately reached $30 \%$ of the previous DG, respectively. This fuel saving would be a significant cost saving which could be relocated into another segment such as investment in more RE sources or extending the battery capacity.

This project was funded by Murata Manufacturing Co.Ltd. and highly supported by Murata engineering team, i.e. Hirofumi Nakata, Toshiya Kawate, Tsuyoshi Matsumoto, Yuta Yamamoto, Hiroyuki Yasui, and Takayuki Miwa. The location to perform the research was provided by Raja Ampat Reseach and Conservation Center (RARCC) at Papua Diving Demo Site owned by Max Ammer. This project was also continuously supported by researchers from Research Centre for Electrical Power and Mechatronics, Indonesian Institute of Sciences (RCEPM-LIPI), i.e. Budi Prawara, Arifin Nur, Rudi Darussalam, Ahmad Rajani, and Dadan Ridwan Saleh.

\section{REFERENCES}

[1] H. Farhangi. IEEE Power Energy Mag., 8(1):18-28 (2010). http://ieeexplore.iee.org/document/5357331/

[2] P. Bajpai, V. Dash. Renew. Sustain. Energy Rev., 16(5):2926-2939 (2012). https://www.sciencedirect.com/science/article/pii/S1364032112001025

[3] M. M. Mahmoud, I. H. Ibrik. Renew. Sustain. Energy Rev., 10(2):128-138 (2006). https://www.sciencedirect.com/science/article/pii/S1364032104001224

[4] A. Wresta, A. Saepudin, A. Santosa, H. Sudibyo, D. Andriani, Kusnadi. J. telecomunication Electron. Comput. Eng., 9(1-5):6-70 (2017). http://journal.utem.edu.my/index.php/jtec/article/view/1837

[5] T. D. Atmaja, G. Pikra. Energy Procedia, 32:74-83 (2013). https://www.sciencedirect.com/science/article/pii/S187661021300012X

[6] A. Mohammed, J. Pasupuleti, T. Khatib, W. Elmenreich. Renew. Sustain. Energy Rev., 44:436-446 (2015). https://www.sciencedirect.com/science/article/pii/S1364032114010879

[7] K. Y. Lau, C. W. Tan, A. H. M. Yatim. Renew. Sustain. Energy Rev., 81(2):2625-2636 (2018). https://www.sciencedirect.com/science/article/pii/S1364032117310110

[8] E. Skoplaki, J. A. Palyvos. Sol. Energy, 83(5):614-624 (2009). https://www.sciencedirect.com/science/article/pii/S0038092X08002788

[9] T. D. Atmaja, R. Darussalam, D. Andriani. Vertical facade PV installation to optimize microgrid system on high rise EV parking lot with $A C$ and DC charging station. International Conference on Sustainable Energy Engineering and Application (ICSEEA), 23-24 October, 2017 (Jakarta, Indonesia, 2017). IEEE, pp. 164-171 (2018). http://ieeexplore.ieee.org/document/8267703/

[10]T. D. Atmaja. Energy Procedia, 32:105-114 (2013). https://core.ac.uk/download/pdf/82215540.pdf

[11]H. Tazvinga, X. Xia, J. Zhang. Sol. Energy, 96:292-299 (2013). https://www.sciencedirect.com/science/article/pii/S0038092X13003046 
[12] K. Kusakana, "Operation cost minimization of photovoltaic-diesel-battery hybrid systems," Energy, 85:645-653 (2015). https://www.sciencedirect.com/science/article/pii/S0360544215004181

[13]E. M. Nfah, J. M. Ngundam, R. Tchinda. Renew. Energy, 32(5):832-844 (2007). https://www.sciencedirect.com/science/article/pii/S0960148106000760

[14] A.L. Galindo Noguera, L. S. Mendoza Castellanos, E. E. Silva Lora, V. R. Melian Cobas. Energy, 142:33-45 (2018). https://www.sciencedirect.com/science/article/pii/S036054421731681X

[15] Y. Hu, P. Solana. Renew. Energy, 51:364-372 (2013). https://www.sciencedirect.com/science/article/pii/S0960148112006313

[16] M. Sechilariu, B.C. Wang, F. Locment. Int. J. Electr. Power Energy Syst., 58:140-149 (2014). https://www.sciencedirect.com/science/article/pii/S0142061514000313

[17] H. Tazvinga, B. Zhu, X. Xia. Sol. Energy, 108:412-420 (2014). https://www.sciencedirect.com/science/article/pii/S0038092X14003740

[18] I.R. Cristóbal-Monreal, R. Dufo-López. Energy Convers. Manag., 119:279-288 (2016). https://www.sciencedirect.com/science/article/pii/S0196890416303004

[19] T.D. Atmaja, Fitriana. Cyber security strategy for future distributed energy delivery system. Proceedings of the 2011 International Conference on Electrical Engineering and Informatics (ICEEI) 17-19 July, 2017 (Bandung, Indonesia, 2011). http://ieeexplore.ieee.org/document/6021635/

[20] C. Yin, H. Wu, F. Locment, M. Sechilariu. Energy Convers. Manag., 132:14-27 (2017). https://www.sciencedirect.com/science/article/pii/S0196890416310135

[21] A. Etxeberria, I. Vechiu, H. Camblong, J.-M. Vinassa. Energy Convers. Manag., 54(1):113-121 (2012). https://www.sciencedirect.com/science/article/pii/S0196890411002779 